\title{
1-Butyl-3-methylimidazolium Salts as New Catalysts to Produce Epoxy-anhydride Polymers with Improved Properties
}

\author{
Mikhail S. Fedoseev, ${ }^{1}$ Matvey S. Gruzdev, ${ }^{2}$ and Lubov F. Derzhavinskaya ${ }^{1}$ \\ ${ }^{1}$ Institute of Technical Chemistry of Ural Branch of the RAS, Perm 614013, Russia \\ ${ }^{2}$ G.A. Krestov Institute of Solution Chemistry of the RAS, Ivanovo 153045, Russia \\ Correspondence should be addressed to Lubov F. Derzhavinskaya; lfderzhavinskaya@mail.ru
}

Received 6 February 2014; Accepted 14 April 2014; Published 13 May 2014

Academic Editor: Jose Ramon Leiza

Copyright (c) 2014 Mikhail S. Fedoseev et al. This is an open access article distributed under the Creative Commons Attribution License, which permits unrestricted use, distribution, and reproduction in any medium, provided the original work is properly cited.

We report the curing process of epoxy oligomers by using isomethyltetrahydrophthalic anhydride catalyzed with 1-butyl-3methylimidazolium salts. Catalytic action has been ascertained to be dependent on the nature of anion. Salts with $\left(\mathrm{Br}^{-}\right)$and $\left(\mathrm{PO}_{4}^{-}\right)$ anions appeared to be most active. Formation of salt adducts with epoxy resin and anhydride is shown. Polymers having higher values of strength and glass transition temperature-as compared with similar epoxy systems cured in the presence of tertiary amines as catalysts-are prepared.

\section{Introduction}

Epoxy-anhydride hot curing binding agents and polymers on the basis are widely applicable in the composite materials' production, in particular, in production of multipurpose organo-, nano- and coal-plastic products [1]. Unlike amine curing binding agents and to binding agents produced in accordance with homopolymerization mechanism, epoxyanhydride binding agents have more advanced technological properties. However, they are effectively cured only in the presence of catalysts such as tertiary amines, Mannich bases, Lewis acids, boron fluoride complexes with aniline, monoethanolamine, and $a$-naphthylamine [2-4]. Many amines used in production processes are volatile and toxic matters and do not meet modern ecological requirements. In addition, tertiary amines, being active compounds, catalyze the polyaddition reaction of epoxy groups immediately after reaction components are mixed, thus leading to their increased viscosity and to shortened pot life. In a number of cases, this phenomenon troubles technological processes of massive production. It has been ascertained also that polymeric materials based on widely used diglycidyl ether of diphenylolpropane (ED-20 resin) produced in the presence of tertiary amines are not sufficiently heat resistant $[5,6]$, whereas polymers produced by means of cation polymerization in the presence of boron fluoride complexes are not heat resistant $[4,7,8]$.

Imidazoles appear to be promising curing catalysts [911]. It has been shown in $[10,12]$ that polymers synthesized using imidazole catalysts and curing agents have larger heat resistance, adhesion, and water resistance. While investigating kinetics and interaction mechanism of epoxides with acid anhydrides in the presence of imidazoles, these imidazoles were shown to be comparable with tertiary amines in catalytic action. For example, 2-ethyl-4-methylimidazole, being highly active curing agent while blended with epoxy resins, does not provide necessary pot life. This fact makes the use of this compound impossible in production of single-package compositions (long-lived at room temperature blends comprised epoxy resin, anhydride, and a catalyst) [13].

To resolve this technological problem, imidazole adducts and their salts with metals $(\mathrm{Cu}, \mathrm{Ni}$, and $\mathrm{Co})$ were synthesized. The mentioned compounds have latent reactivity (latency) at low temperatures and disintegrate at high temperatures into initial constituents of adducts, while catalyzing curing reactions of polymers [12-14]. 1,3-Dialkylimidazole salts, as being ionic liquids, can, arguably, also be regarded as adducts of this kind. In line with up-to-date ideas, ionic liquids based 
on imidazolium salts are permolecular polymeric structures with a high degree of self-organization. These ionic liquids are comprised only of ions and have lipophilic properties in a wide temperature diapason [15].

Recently, one of priority trends of the modern "green chemistry" is the use of ionic liquids as promising mediums for organic reactions [16]. The use of ionic liquids as catalysts and curing agents for epoxy resins and production of multipurpose materials is one of trends in this field [17-22]. For example, the work [23] describes a unique result attained by using ionic liquid. An ionic liquid type imidazolium catalyst enhanced the conductivity of epoxyanhydride resin based electrical conductive adhesives (ECAs) by more than two orders of magnitude compared with common imidazole compounds. Percolation growth dynamics study combined with epoxy curing kinetics results indicates that the enhancement of conductivity was attributed to the higher percolation efficiency within ionic liquid catalyzed ECAs. In work [24], ionic liquids differing in the length of alkyl chain at imidazolium cation (butyl or decyl) with various ions, for example, $\mathrm{N}(\mathrm{CN})_{2}{ }^{-},\left(\mathrm{BF}_{4}{ }^{-}\right)$, and $\left(\mathrm{Cl}^{-}\right)$, were used as curing agents for epoxy compositions. By using various physical methods, thermal and thermomechanical properties of polymers were ascertained to be influenced by the nature and by concentration of an anion. The highest glass transition temperature $\left(170^{\circ} \mathrm{C}\right)$ was attained for materials cross-linked with ion liquid containing dicyandiamide anion. Molecular ionic liquid, that is, 1-ethyl-3-methylimidazolium chloride ([EMIM] Cl), and eutectic mixture of imidazole with choline chloride (IM $+\mathrm{ChCl}$ ) have been used as epoxy resin hardeners. An influence of [EMIM] Cl and IM $+\mathrm{ChCl}$ content on pot life of epoxy compositions and runs of crosslinking process has been evaluated using DSC and ARES rheometry techniques. Epoxy compositions with [EMIM]Cl showed latent properties (pot life up to 50 days) while the systems with IM $+\mathrm{ChCl}$ gelled after few days. Composite epoxy materials cross-linked with [EMIM]Cl exhibited more elastic properties (lower $T_{g}$ and higher $\tan \delta$ values) and generally better mechanical features than those hardened with imidazole + choline chloride eutectic mixture [25].

This work aims at investigating 1-butyl-3-methyl imidazolium salts as latent catalysts for anhydride-cured epoxy oligomers and at studying the properties of polymers produced on their basis.

\section{Experimental Method}

Preparation of epoxy polymers was performed by using chemical interaction of epoxy oligomers: diphenylolpropane diglycidylether (ED-20 resin) and oligodienetetraurethane diepoxide (PDI-3AK), with isomethyltetrahydrophthalic anhydride (IMTHPA) under the action of catalysts (salts of 1-butyl-3-methylimidazolium, hereinafter as SBMI) in accordance with general formula as follows:

$$
\left[\mathrm{H}_{3} \mathrm{C}-\mathrm{N}-\mathrm{N}^{+} \sim \mathrm{CH}_{3}\right] \mathrm{X}^{-}
$$

where $\mathrm{X}$ stands for $\mathrm{Br}, \mathrm{BF}_{4}, \mathrm{PO}_{4}$, and $\mathrm{HSO}_{4}$.
The mentioned salts with various ions were synthesized on the basis of 1-methylimidazole in accordance with the upgraded method described in [26].

Epoxy-anhydride compositions comprised epoxy oligomer, curing agent (IMTHPA) taken in equimolar ratio, and catalyst (0.5-1 wt.) were mixed in laboratory mixer at $40-$ $50^{\circ} \mathrm{C}$ under vacuum for $15-20 \mathrm{~min}$. The reaction mix was casted into metallic fill-out forms and kept in thermostat until complete curing. The curing was performed at temperature values determined from reaction kinetics by using the DSC method on the DSC $822^{\mathrm{e}}$ calorimeter (Mettler Toledo, Switzerland) in dynamic mode at $5^{\circ} \mathrm{C} / \mathrm{min}$ heating rate in temperature interval of $25-300^{\circ} \mathrm{C}$. Initial temperature $\left(T_{\text {initial }}\right)$, temperature of maximal heat-evolution $\left(T_{\max }\right)$, and heat-evolution power versus time were registered in temperature profiles. These data resulted in calculation of heat efficiency of the reaction (based on peak area) and of the effective activation energy $(E)$.

Strain-strength characteristics of the cured polymers, namely, tensile strength and relative elongation, were determined at a set-point temperature and at $0.056 \mathrm{~s}^{-1}$ stretching rate on the Instron 3565 universal testing machine (Instron, Great Britain).

The glass transition temperature $T_{g}$ was determined by the method of thermomechanical analysis on the UIP-70 device (Russia) in temperature interval $20-200^{\circ} \mathrm{C}$ at the scanning rate $5^{\circ} \mathrm{C} / \mathrm{min}$ in the dilatometry regime.

Thermal characteristics of polymers were determined on the MOM Q-1500D (Paulik-Paulik-Erdey) derivatograph. The programmed heating was performed at $5^{\circ} \mathrm{C} / \mathrm{min}$ rate in interval of $20-1000^{\circ} \mathrm{C}$ in the air. Aluminium oxide was used as a standard. Heat resistance of polymers was appraised from $5 \%$ and $10 \%$ loss of mass.

The water uptake of polymers was appraised from an increase in a specimen's mass in water at $25^{\circ} \mathrm{C}$ for $24 \mathrm{~h}$.

Pot life $t^{*}$ (inductive effect) of mixed reaction compositions was appraised from a variation in viscosity while using the rotational rheotest- 2 viscometer (Germany) with coneplate unit at constant $180 \mathrm{~s}^{-1}$ shear rate at $25 \pm 0.5^{\circ} \mathrm{C}$.

Chemical interaction between 1-butyl-3-methylimidazolium salts and epoxy composition's components (ED-20, PDI$3 A K$, and IMTHPA) was investigated by means of FTIRspectroscopy method using IFS-66 spectrometer (Bruker, Germany).

\section{Results and Discussions}

Due to availability of pyridine and pyrrole atoms in the structure of imidazole molecules, these molecules exhibit both acid and basic properties. This fact enables using these compounds in various chemical reactions. In $[27,28]$, reactions of mono- and diepoxy compounds with various imidazoles are investigated; also, a bimodal curing mechanism for polymers supposing formation of intermediate adducts (epoxide-imidazole) being true catalysts of curing reactions is offered. Recently [10], the nonsubstituted imidazoles were ascertained to form adducts also with acid anhydrides catalyzing polyaddition reaction of oligomer's epoxy group with 


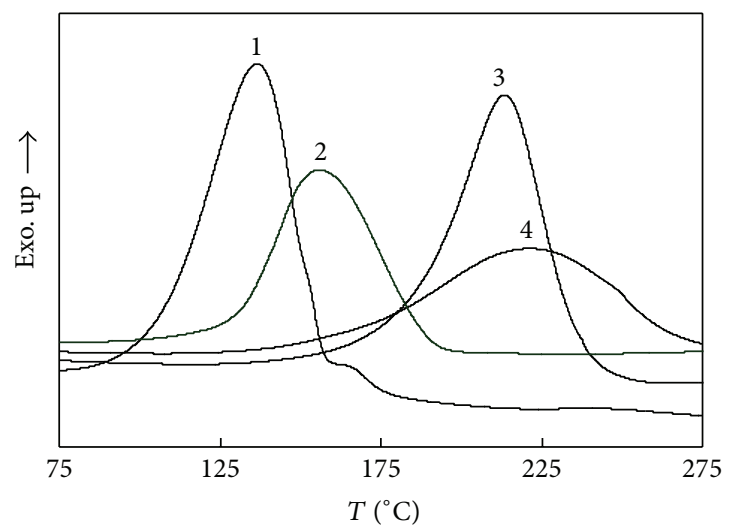

FIGURE 1: DSC curves of curing reaction of IMTHPA-cured ED-20 resin in the presence of catalysts: (1) 1-butyl-3-methylimidazolium bromide; (2) 1-butyl-3-methylimidazolium orthophosphate; (3) 1-butyl-3-methylimidazolium tetrafluoroborate; (4) 1-butyl-3-methylimidazolium sulfate.

TABLE 1: Kinetics parameters of interaction reaction of ED-20 resin and IMTHPA under the action of 1-butyl-3-methyl imidazolium salts with various inorganic anions in molecule, of 1-methyl imidazole and of 2,4,6-tris(dimethylaminomethyl)phenol.

\begin{tabular}{lcccc}
\hline Catalyst & $T_{\text {in }},{ }^{\circ} \mathrm{C}$ & $T_{\text {pic }},{ }^{\circ} \mathrm{C}$ & $Q, \mathrm{~J} / \mathrm{g}$ & $E, \mathrm{~kJ} / \mathrm{mol}$ \\
\hline 1-Butyl-3-methylimidazolium tetrafluoroborate & 120 & 214 & 387 & 317 \\
1-Butyl-3-methylimidazolium sulfate & 120 & 222 & 331 & 100 \\
1-Butyl-3-methylimidazolium phosphate & 82 & 156 & 322 & 95 \\
1-Butyl-3-methylimidazolium bromide & 70 & 137 & 350 \\
1-Methylimidazole & 45 & 125 & 312 \\
2,4,6-Tris(dimethylaminomethyl)phenol & 75 & 145 & 87 \\
\hline
\end{tabular}

anhydride epoxy group followed by formation of a crosslinked polymer. Investigation of interaction kinetics of ED-20 and PDI-3AK epoxy oligomers with IMTHPA curing agent in the presence of 1-butyl-3-methyl imidazolium salts by using DSC method has shown these oligomers to be catalysts of polyaddition reaction. Their catalytic activity is somewhat lower as compared with tertiary amines and imidazoles. The DSC temperature profiles (Figure 1) have enabled ascertaining temperature-time conditions for the curing reaction. Kinetics parameters are presented in Table 1. As is apparent from the obtained data, initial temperature of reaction and maximal heat-evolution are dependent on the nature of anion in salt molecule. 1-Butyl-3-methylimidazolium bromide and 1-butyl-3-methylimidazolium phosphate proved to be most active catalysts $\left(T_{\text {in }}=70^{\circ} \mathrm{C}\right.$ and $82^{\circ} \mathrm{C}$, resp.). Salts with $\mathrm{BF}_{4}$ and $\mathrm{HSO}_{4}$ anions start catalyzing the interaction reaction between resin and anhydride at a higher temperature $\left(120^{\circ} \mathrm{C}\right)$. 1-Butyl-3-methylimidazolium bromide, as the most active catalyst, was selected for further investigations.

As expected, catalytic action of 1-butyl-3-methylimidazolium bromide is lower as compared with that of 1-methylimidazole being initial product of the given salt (Figure 2). This is attributed to the fact that the salt has latent properties to a greater extent as compared with 1-methylimidazole; also, interaction mechanism during synthesis of epoxy-anhydride polymers has certain distinctions. To ascertain these distinctions, interaction between 1-butyl-3-methylimidazolium

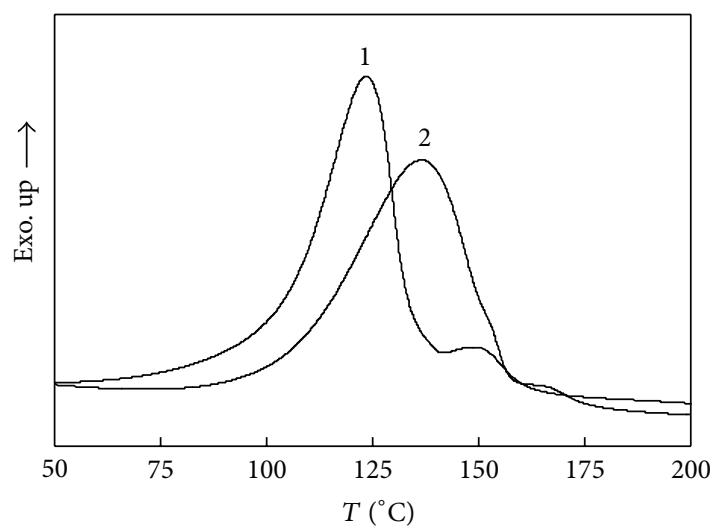

FIGURE 2: DSC curves of curing reaction of IMTHPA-cured ED-20 resin in the presence of catalysts: (1) 1-methylimidazole; (2) 1-butyl3-methylimidazolium bromide.

bromide and epoxy compositions' components (ED-20, PDI$3 \mathrm{AK}$, and IMTHPA oligomers) was investigated by using the FTIR-spectroscopy method. The FTIR spectra of reaction mixes are presented in Figures 3, 4, and 5. Analysis of the spectra has shown that, on interaction between 1-butyl-3methyl imidazolium bromide and IMTHPA at $100^{\circ} \mathrm{C}$, the reaction proceeds with participation of anhydride group with subsequent formation of oligoamides, polyanhydrides, and 


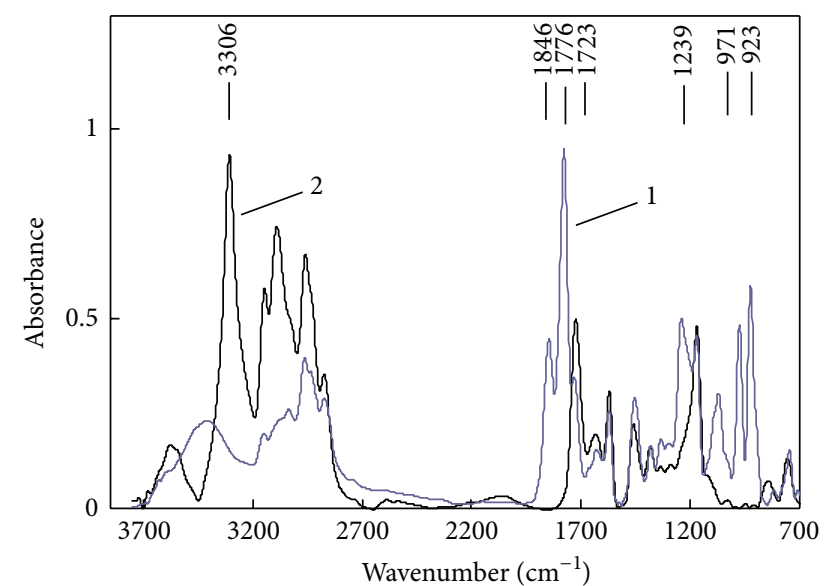

FIGURE 3: FTIR-spectrum of reaction mixture "1-butyl-3-methylimidazolium bromide - IMTHPA": (1) initial mixture; (2) kept for $5 \mathrm{~h}$ at $100^{\circ} \mathrm{C}$.

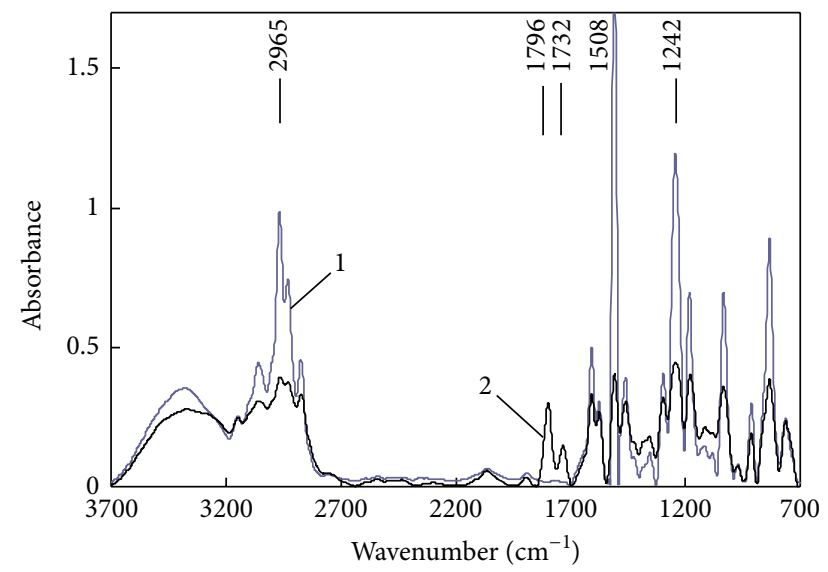

FIGURE 4: FTIR-spectrum of reaction mixture "1-butyl-3-methylimidazolium bromide - ED-20 resin": (1) initial mixture; (2) kept for $5 \mathrm{~h}$ at $100^{\circ} \mathrm{C}$.

ketones. The produced adducts are stable viscous liquids and active catalysts of the epoxy-anhydride binding agent's curing process (Figure 6). Most likely, these adducts can be regarded as complexes with the charge transfer. Similar complexes were produced in [23], on interaction between dicarboxylic acid anhydrides and tertiary amines. They can transform to polyanhydrides, polyesters, oligoamides, and oligoalkyl(aryl)ketones with a system of conjugate bonds. Judging from the DSC diagrams of the same type, the curing reaction's mechanism of catalysis in the presence of adducts produced on the basis of 1-butyl-3-methylimidazolium bromide and on the basis of the earlier investigated 2-ethyl-4methylimidazole [10] is the same mechanism.

A more complicated character is observed in interaction mechanism between 1-butyl-3-methylimidazolium bromide and ED-20 epoxy oligomers, especially with PDI-3AK containing four urethane groups and two end-capped epoxy groups in its molecule. This is attributed to peculiarities in their structure and to the difference in reactivity of

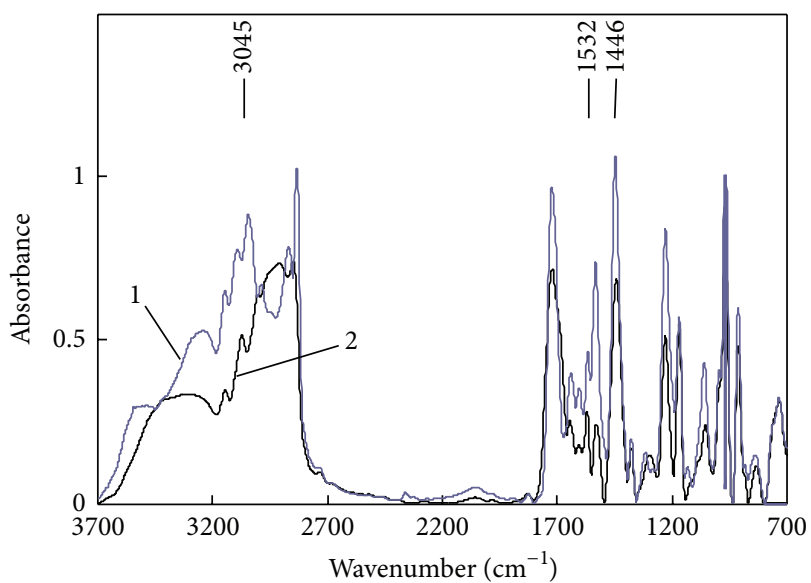

FIGURE 5: FTIR-spectrum of reaction mixture "1-butyl-3-methylimidazolium bromide-PDI-3AK”: (1) initial mixture; (2) kept for $5 \mathrm{~h}$ at $100^{\circ} \mathrm{C}$.

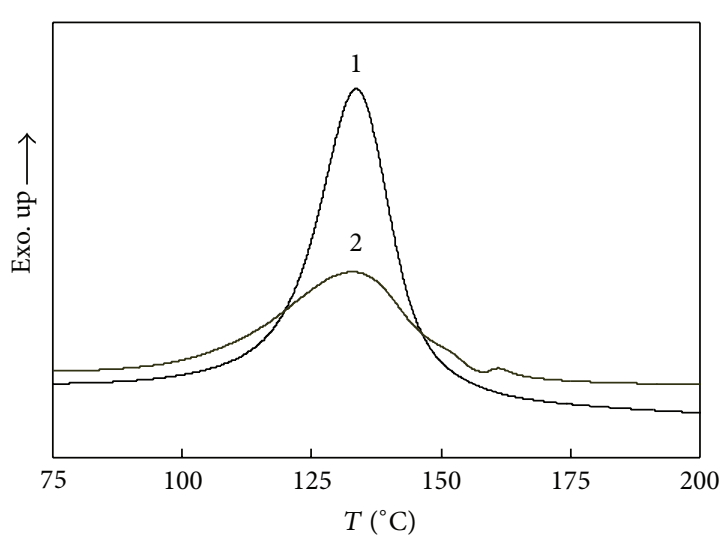

FIGURE 6: DSC curves of curing reaction of ED-20 resin with IMTHPA hardener in the presence of interaction products: (1) 2ethyl-4-methylimidazole + IMTHPA; (2) 1-butyl-3-methylimidazolium bromide + IMTHPA.

the end-capped epoxy groups. With this connection, we had set optimal temperature regimes for these reactions. It was expedient to do this, while also keeping in mind that compounds for electronic and radioengineering devices, as well as polymeric and sealing materials for various purposes, were designed on the basis of the given polymers [28-30].

Distinction in reactive capability of catalysts exerts appreciable influence on rheological properties of reaction mixes. Comparable results are presented in Figure 7. As is apparent from viscosity curves registered at room temperature, reaction mixes' pot life regarded as a period of time needed for the mixes to attain viscosity value of 140 Pas was appreciably dependent on the nature of the catalyst. The lowest pot life $\left(t_{1}^{*}=30 \mathrm{~h}\right)$ has a composition containing tertiary amine2,4,6-tris(dimethylaminomethyl)phenol. The $N$-substituted 1-methyl imidazole as a high-temperature catalyst enables extending pot life of the epoxy-anhydride composition up to $t_{2}^{*}=72 \mathrm{~h}$ at room temperature. Pot life of the composition 


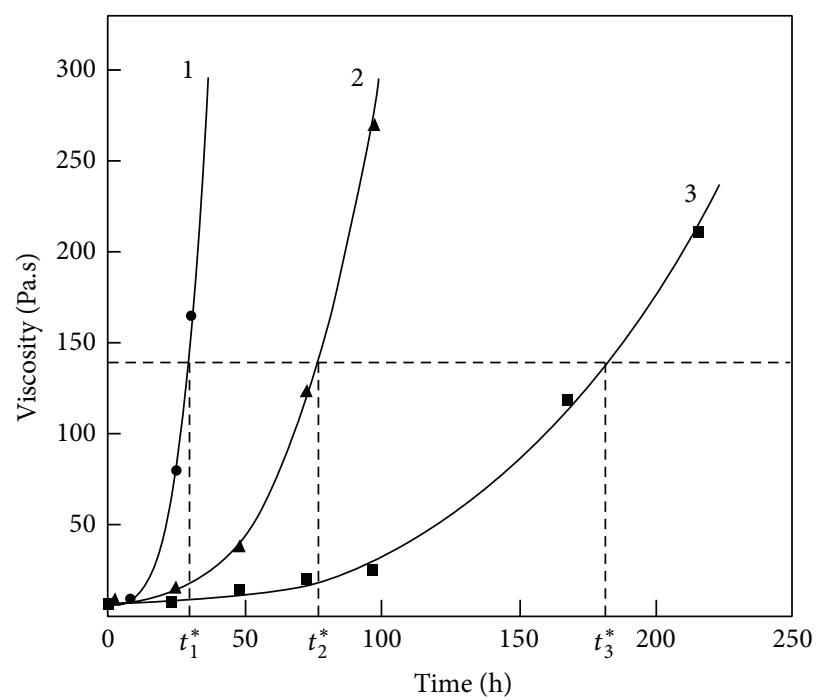

Figure 7: Dynamic viscosity variation of epoxy-anhydride compositions at $T=25^{\circ} \mathrm{C}$ versus time in the presence of catalysts: (1) $2,4,6$ tris(dimethylaminomethyl)phenol; (2) methylimidazole; (3) 1-butyl-3-methylimidazolium bromide.

with the SBMI-Br catalyst $\left(t_{3}^{*}\right)$ attains $178 \mathrm{~h}$; that is, this catalyst can be regarded as a latent catalyst.
Action mechanism of the known amine catalyst, namely, 2,4,6-tris(dimethylaminomethyl)phenol, is represented in (2).

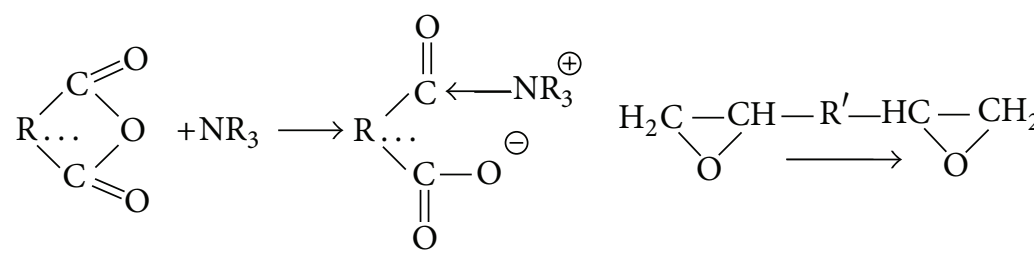<smiles>[R]C(=O)C(=O)OC(O)O</smiles>

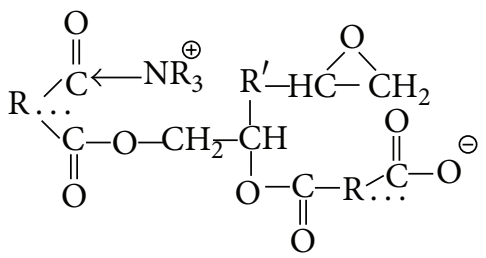

Formation/action mechanism of adducts with participation of 1-substituted imidazoles differs from that of tertiary amine. In [28], formation outline of an adduct resulting from reaction of 1-methylimidazole with phenyldiglycidyl ether at
$1: 1$ ratio is represented. In this reaction, the epoxy group is attacked by more basic pyridine group of nitrogen:<smiles></smiles> 
TABLE 2: Rheological, physic-mechanical, thermal properties of epoxy polymers.

\begin{tabular}{|c|c|c|c|c|c|c|c|c|}
\hline \multirow[t]{2}{*}{ Composition, wt.\% } & \multirow{2}{*}{$t^{*}, \mathrm{~h}$} & \multirow{2}{*}{$\begin{array}{l}\text { Synthesis } \\
\text { conditions }\end{array}$} & \multirow[t]{2}{*}{$T_{g},{ }^{\circ} \mathrm{C}$} & \multicolumn{2}{|c|}{$\begin{array}{l}\text { Physic-mechanical properties } \\
\text { under stretching }\end{array}$} & \multirow{2}{*}{$\begin{array}{l}\quad \text { Water } \\
\text { absorption, } 24 \mathrm{~h} \text {, } \\
25^{\circ} \mathrm{C}, \% \text { mas. }\end{array}$} & \multicolumn{2}{|c|}{$\begin{array}{l}T,{ }^{\circ} \mathrm{C} \\
\text { mass loss }\end{array}$} \\
\hline & & & & $\sigma, \mathrm{mPa}$ & $\varepsilon, \%$ & & $5 \%$ & $10 \%$ \\
\hline $\begin{array}{l}\text { ED- } 20-55,5 \\
\text { IMTHPA-44,0 } \\
\text { SBMI-Br-0,5 }\end{array}$ & 178 & $\begin{array}{l}120^{\circ} \mathrm{C}, 3 \mathrm{~h} \\
160^{\circ} \mathrm{C}, 3 \mathrm{~h}\end{array}$ & 135 & 60 & 12 & 0,17 & 330 & 360 \\
\hline $\begin{array}{l}\text { ED-20-55,5 } \\
\text { IMTHPA-44,0 } \\
\text { 2,4,6-Tris(dimethylaminomethyl)phenol-0,5 }\end{array}$ & 30 & $\begin{array}{l}120^{\circ} \mathrm{C}, 3 \mathrm{~h} \\
160^{\circ} \mathrm{C}, 3 \mathrm{~h}\end{array}$ & 105 & 55 & 10 & 0,11 & 335 & 360 \\
\hline $\begin{array}{l}\text { PDI-3AK-93 } \\
\text { IMTHPA-6 } \\
\text { SBMI-Br-1 }\end{array}$ & 240 & $\begin{array}{l}80^{\circ} \mathrm{C}, 72 \mathrm{~h} \\
120^{\circ} \mathrm{C}, 3 \mathrm{~h}\end{array}$ & -82 & 4 & 415 & - & 300 & 340 \\
\hline $\begin{array}{l}\text { PDI-3AK-93 } \\
\text { IMTHPA-6 } \\
\text { 2,4,6-Tris(dimethylaminomethyl)phenol-1 }\end{array}$ & 40 & $\begin{array}{l}80^{\circ} \mathrm{C}, 72 \mathrm{~h} \\
120^{\circ} \mathrm{C}, 3 \mathrm{~h}\end{array}$ & -76 & 2,2 & 142 & - & 305 & 340 \\
\hline
\end{tabular}

The adduct initiates further polymerization of phenyldiglycidyl ether.
The work [31] shows how reaction between ionic liquid $\left(\mathrm{N}, N^{\prime}\right.$-dioctadecylimidazolium iodide) and bisphenol diglycidylether A (DGEBA) forms adducts:<smiles></smiles><smiles></smiles>

By using the FTIR-spectroscopy, the reaction between DGEBA and amine curing agent $\left(4,4^{\prime}\right.$-methylenebis(3chloro-2,6-diethylaniline) was shown to proceed at higher temperatures $\left(140-180^{\circ} \mathrm{C}\right)$.

Currently, formation/action mechanism of SBMI-Br adducts, namely of epoxy oligomer and of anhydride, has not been studied. Conditionally, the following outline for the curing of epoxy oligomers by means of acid anhydride under the action of SBMI-Br can be presented. On the first stage, variously comprised adducts of oligomer and of anhydride with SBMI-Br catalyst are formed. On the second stage, catalysis initiated by adducts occurs followed by formation of linear and branched polymers. On the third stage, the structure of a cross-linked polymer and its physic-mechanical properties are finally formed.
While using the SBMI-Br catalyst, a number of polymers were synthesized. Their physic-mechanical, thermal, and thermal-physic properties, as well as water-resistance were investigated (Table 2).

Compositions with the 2,4,6-tris(dimethylaminomethyl) phenol are presented for comparison. These data indicate physic-mechanical, thermal, and thermal-physic properties of polymers synthesized using the SBMI-Br and 2,4,6tris(dimethylaminomethyl)phenol catalysts to be approximately at the same level.

As regards the influence of catalysts on structure formation, an increase in glass transition temperature by $30^{\circ} \mathrm{C}$, and, respectively, an increase in heat resistance of polymers produced in the presence of the SBMI-Br were revealed. Thus, the 1-butyl-3-methyl imidazolium bromide salt can also be 
regarded as a structural modifier. Strength and critical strain values of elastomer based on PDI-3AK and SBMI-Br increase almost 2-fold as compared with an elastomer synthesized in the presence of tertiary amine.

The increase in strength is, probably, attributed to formation of strong intermolecular interaction within polymer, in particular, of donor-acceptor bonds with energy values attaining $40 \mathrm{kcal} / \mathrm{mol}$. This phenomenon leads to an increase in cohesion and, respectively, in strength properties of polymers. Glass transition temperature of polymers is $-76^{\circ} \mathrm{C}$ and $-82^{\circ} \mathrm{C}$; this fact enables classifying the given polymers as frost-resistive.

\section{Conclusions}

Results of investigations in 1-butyl-3-methylimidazolium salts (ionic liquids) as catalysts in synthesis of epoxyanhydride polymers have enabled ascertaining the following: (a) these salts are comparable with tertiary amines in catalytic action; (b) unlike tertiary amines, they are latent catalysts. Due to this, pot life of reactive mixes containing the given salts increases 5 - to 6 -fold at $20 \pm 5^{\circ} \mathrm{C}$, thus enabling producing the so-termed single-package compositions featured by high stability. Chemical interaction of one of most promising salt, namely, 1-butyl-3-methylimidazolium bromide, with (a) ED-20, (b) oligodienetetraurethane diepoxide (PDI-3AK), and (c) IMTHPA as curing agents, was investigated by DSC and FTIR-spectroscopy methods. Formation of respective adducts being true catalysts and curing agents for epoxy oligomers was shown. Physic-mechanical, thermal, and structural characteristics of epoxy polymers cured with 1butyl-3-methylimidazolium bromide were determined: tensile strength of polymers based on ED-20 resin, IMTHPA, and 1-butyl-3-methyl imidazolium bromide- $60 \mathrm{mPa}$, relative elongation $10-12 \%$, and glass transition temperature $-135^{\circ} \mathrm{C}$. Physic-mechanical characteristics are appraised as being at the level of polymers produced in the presence of tertiary amines; for example, in glass transition temperature, polymers based on ionic liquid outperform these by $30^{\circ} \mathrm{C}$.

Thus, 1-butyl-3-methylimidazolium bromide can be regarded also as a structural modifier which, during synthesis of polymer, is embedded into polymeric chain, while imparting more strength and density of package to it. This leads to an increase in glass transition temperature and, respectively, in heat resistance. The obtained results are in accordance with literature data.

Thermal properties of polymers, judging from data of differential thermal analysis, are not dependent on the nature of the used catalyst but mainly depend on the nature of epoxy oligomer. It was shown that polymers on the basis of the PDI-3AK were frost-resisting elastomers with glass transition temperature $-76^{\circ} \mathrm{C} \div-82^{\circ} \mathrm{C}$.

\section{Conflict of Interests}

The authors declare that there is no conflict of interests regarding the publication of this paper.

\section{References}

[1] G. Lubin, Ed., Handbook of Composites, Van Nostrand Reinhold Company, 1982.

[2] H. Lee and K. Neville, Handbook of Epoxy Resins, M. Energy, Moscow, Russia, 1973 (Russian).

[3] R. A. Dickie, S. S. Labana, and R. S. Bauer, Eds., Cross-Linked Polymers, American Chemical Society, Washington, DC, USA, 1988.

[4] M. A. Sinelnikova, E. P. Volkova, and E. M. Shved, "The influence of epoxy resin-catalyst ratio on the rate of anhydride curing of ED-20 resin in the presence of boron trifluoride with benzylamine," Journal of Chemistry and Chemical Technology, vol. 3, pp. 115-118, 2002.

[5] P. A. Sitnikov, A. G. Belykh, M. S. Fedoseev, I. N. Vaseneva, and A. V. Kuchin, "Modification of epoxy-anhydride polymers with aluminum oxide," Russian Journal of Applied Chemistry, vol. 81, no. 5, pp. 826-829, 2008.

[6] O. I. Petko and I. P. Petko, "Epoxy binding agents for production of variously shaped fiberglass plastics and figures of revolution," Plastics, vol. 10, pp. 38-39, 2008.

[7] V. M. Mikhal'chuk, T. V. Kryuk, and A. N. Nikolaevskii, "Inhibition of thermal and thermo-oxidative destruction of cation-polymerized epoxy polymers by oxides and metal salts," Russian Journal of Applied Chemistry, vol. 69, no. 6, pp. 10081013, 1996.

[8] V. M. Mikhal'chuk, T. V. Kryuk, and A. N. Nikolaevskii, "Stabilization of epoxy polymers by synergetic mixtures of phenol anti-oxidants and metals' compounds," Russian Journal of Applied Chemistry, vol. 69, no. 6, pp. 1354-1368, 1996.

[9] K. Kowalczyk and T. Spychaj, "Ionic liquids as convenient latent hardeners of epoxy resins," Polimery, vol. 48, no. 11-12, pp. 833835, 2003.

[10] M. S. Fedoseev, L. F. Derzhavinskaya, and V. N. Strel'nikov, "Curing of epoxy-anhydride compositions in the presence of imidazoles," Russian Journal of Applied Chemistry, vol. 83, no. 8, pp. 1303-1307, 2010.

[11] J. M. Barton, "Aspects of epoxy resin curing reactions," Macromolecular Symposia, vol. 7, no. 1, pp. 27-36, 1987.

[12] M. S. Fedoseev and I. V. Zvereva, "Investigation in imidazole and benzotriazole derivatives as catalysts for curing of epoxyanhydride binding agents," Russian Journal of Applied Chemistry, vol. 81, no. 5, pp. 799-802, 2008.

[13] F. Wang, J. Xiao, J.-W. Wang, and S.-Q. Li, "A novel imidazole derivative curing agent for epoxy resin: synthesis, characterization, and cure kinetic," Journal of Applied Polymer Science, vol. 107, no. 1, pp. 223-227, 2008.

[14] A. V. Pocius, Adhesion and Adhesives Technology: An Introduction, Carl Hanser, Munich, Germany, 2002.

[15] A. A. Zanin, "Ionic liquids in synthesis of nanoobjects," Progress in Chemistry Journal, vol. 79, no. 6, pp. 516-531, 2010.

[16] P. J. Dyson and T. J. Geldbach, Metal Catalyzed Reactions in Ionic Liquids, Springer, Dordrecht, The Netherlands, 2005.

[17] J. Lu, F. Yan, and J. Texter, "Advanced applications of ionic liquids in polymer science," Progress in Polymer Science, vol. 34, no. 5, pp. 431-448, 2009.

[18] P. Kubisa, "Ionic liquids in the synthesis and modification of polymers," Journal of Polymer Science A: Polymer Chemistry, vol. 43, no. 20, pp. 4675-4683, 2005.

[19] J. P. Pascault and R. J. J. Williams, Eds., Epoxy Polymers, WileyVCH, Weinheim, Germany, 2010. 
[20] J. Sanes, F.-J. Carrión-Vilches, and M.-D. Bermúdez, "New epoxy-ionic liquid dispersions. Room temperature ionic liquid as lubricant of epoxy resin-stainless steel contacts," e-Polymers, vol. 7, no. 1, pp. 48-59, 2007.

[21] J. Sanes, F. J. Carrión, and M. D. Bermúdez, "Effect of the addition of room temperature ionic liquid and $\mathrm{ZnO}$ nanoparticles on the wear and scratch resistance of epoxy resin," Wear, vol. 268, no. 11-12, pp. 1295-1302, 2010.

[22] K. Matsumoto and T. Endo, "Synthesis of ion conductive networked polymers based on an ionic liquid epoxide having a quaternary ammonium salt structure," Macromolecules, vol. 42, no. 13, pp. 4580-4584, 2009.

[23] X. Zhang, H. Sun, C. Yang, K. Zhang, M. M. F. Yuen, and S. Yang, "Highly conductive polymer composites from roomtemperature ionic liquid cured epoxy resin: effect of interphase layer on percolation conductance," RSC Advances, vol. 3, no. 6, pp. 1916-1921, 2013.

[24] H. Maka, T. Spychaj, and R. Pilawka, "Epoxy resin/ionic liquid systems: the influence of imidazolium cation size and anion type on reactivity and thermomechanical properties," Industrial and Engineering Chemistry Research, vol. 51, no. 14, pp. 5197-5206, 2012.

[25] H. Maka and T. Spychaj, "Epoxy resin cross-linked with conventional and deep eutectic ionic liquids," Polimery, vol. 57, no. 6, pp. 456-462, 2012.

[26] M. S. Gruzdev, L. M. Ramenskaya, U. V. Chervonova, and R. S. Kumeev, "Preparation of 1-butyl-3-methylimidazolium salts and study of their phase behavior and intramolecular intractions," Russian Journal of General Chemistry, vol. 79, no. 8, pp. 1720-1727, 2009.

[27] V. Jisova, "Curing mechanism of epoxides by imidazoles," Journal of Applied Polymer Science, vol. 34, no. 7, pp. 2547-2558, 1987.

[28] M. Ghaemy and S. Sadjady, "Kinetic analysis of curing behavior of diglycidyl ether of bisphenol a with imidazoles using differential scanning calorimetry techniques," Journal of Applied Polymer Science, vol. 100, no. 4, pp. 2634-2641, 2006.

[29] M. S. Fedoseev, V. V. Tereshatov, and L. F. Derzhavinskaya, "Polymeric materials on the basis of oligodieneurethane epoxy oligomers," Russian Journal of Applied Chemistry, vol. 83, no. 8, pp. 1261-1263, 2010.

[30] S. N. Gladkikh, E. N. Basharina, and L. I. Naumova, "New compounds for cold impregnation of spooled products," Glues, Sealants, Technologies Journal, vol. 9, pp. 26-30, 2009.

[31] B. G. Soares, S. Livi, J. Duchet-Rumeau, and J.-F. Gerard, "Synthesis and characterization of epoxy/MCDEA networks modified with imidazolium-based ionic liquids," Macromolecular Materials and Engineering, vol. 296, no. 9, pp. 826-834, 2011. 

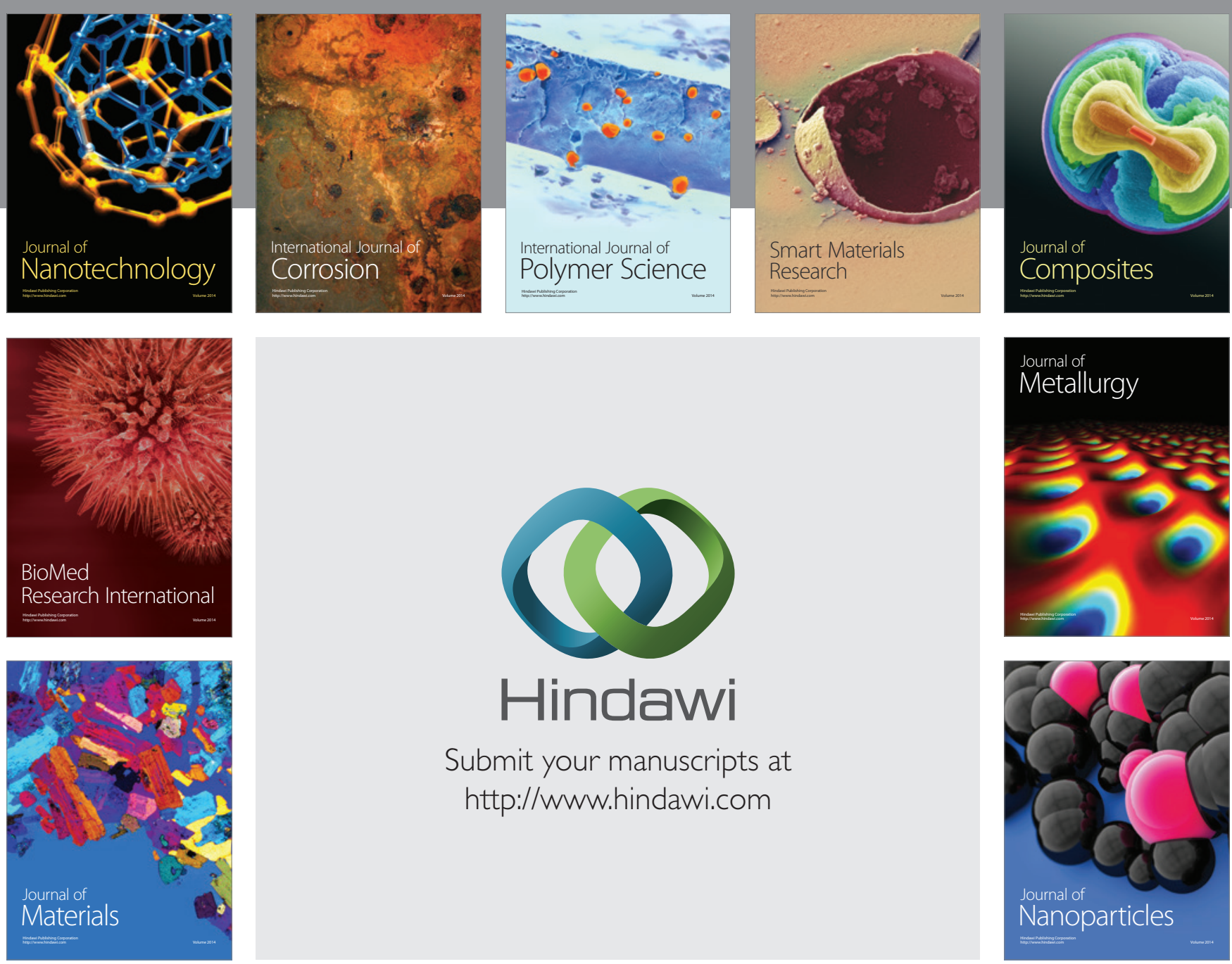

Submit your manuscripts at http://www.hindawi.com
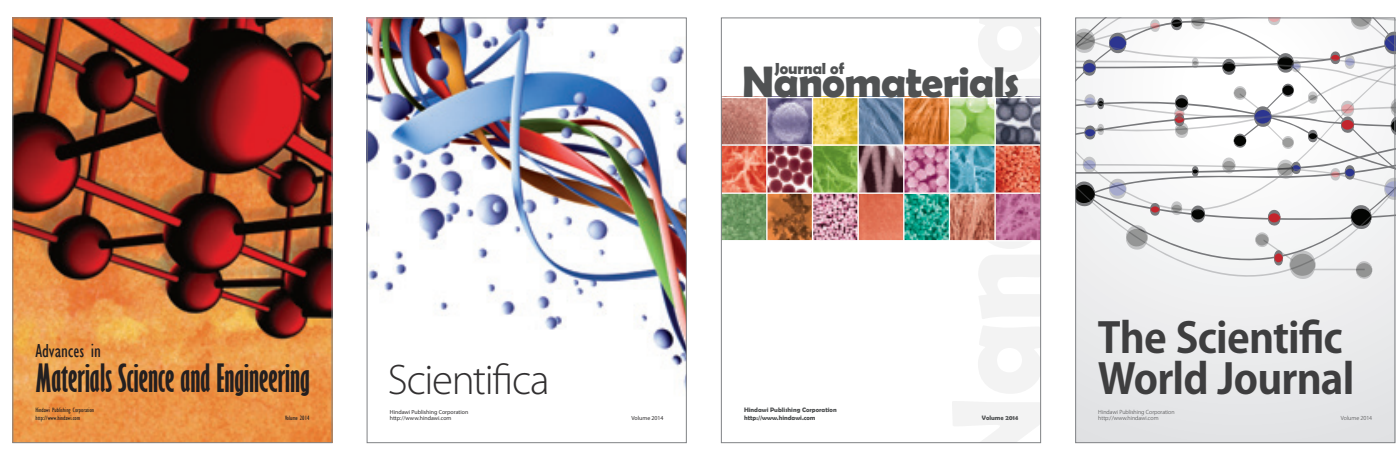

\section{The Scientific World Journal}
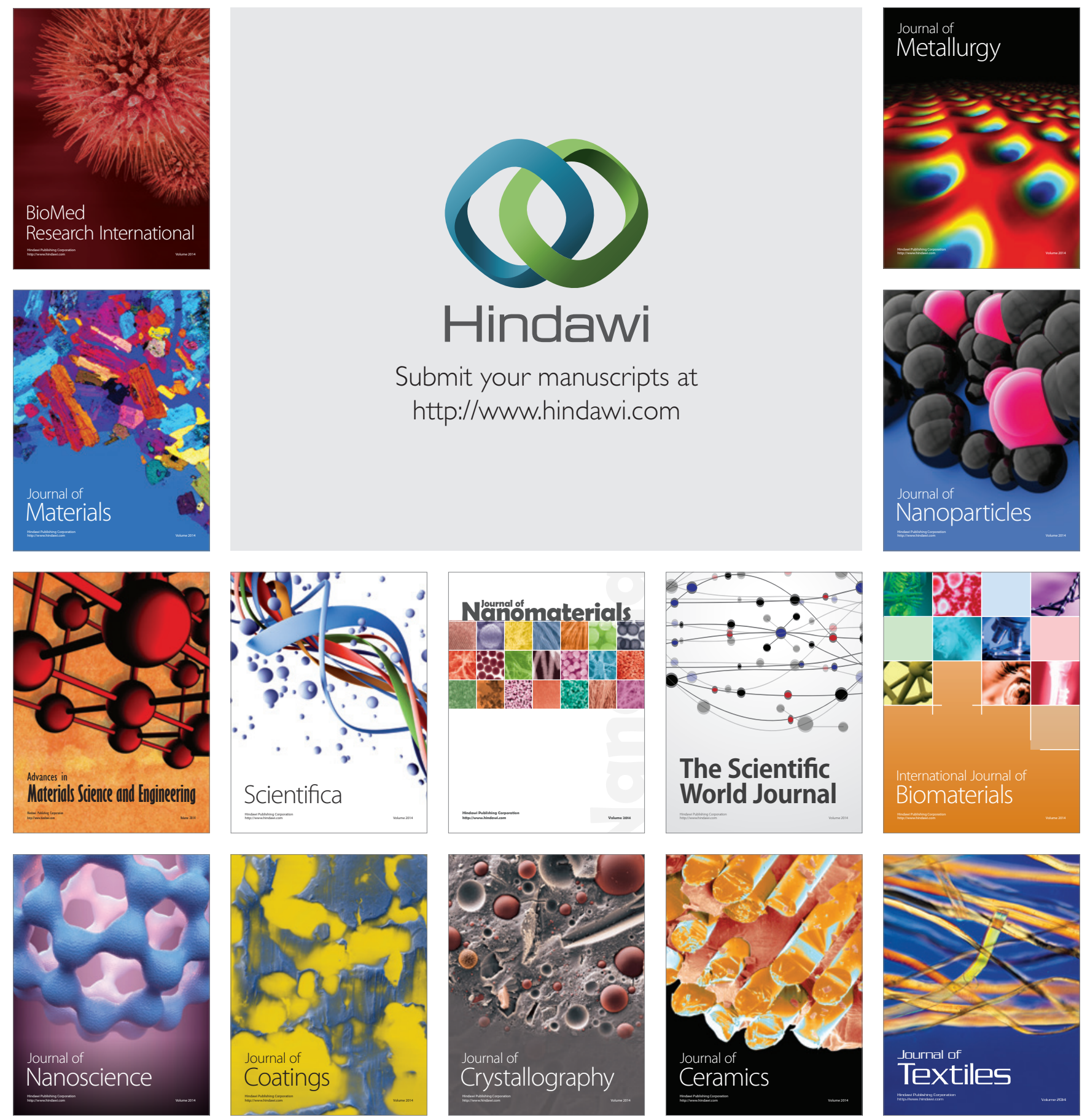